\title{
P-0404: Real world efficacy and safety of empagliflozin in Malaysian type 2 diabetes mellitus patients
}

\section{KC Chooi', N Musa', YL Wong' ${ }^{2}$, M Sivalingam², ATB Tan'}

${ }^{1}$ Endocrine Unit, University of Malaya Medical Centre; ${ }^{2}$ Boehringer Ingelheim Malaysia

\section{BACKGROUND}

- The empagliflozin clinical trial program (EMPA-REG) demonstrated reductions in glucose, body weight, blood pressure and insulin requirements in type 2 diabetes (T2DM) patients ${ }^{1,2}$.

- In Malaysia, real world outcomes data on empagliflozin has not been published.

\section{AIM}

To assess the real world efficacy and safety of empagliflozin in Malaysian T2DM patients.

\section{METHOD}

- This study was conducted at the University of Malaya Medical Centre, a tertiary referral hospital in Kuala Lumpur, Malaysia.

- Empagliflozin prescription data from March to September 2016 was extracted from outpatient records.

- Demographic details, $\mathrm{HbA}_{1 \mathrm{c}}$, weight, blood pressure (BP), glomerular filtration rate (GFR), lipids, insulin use, history of cardiovascular disease (CVD) and adverse events were analysed.

- Patients that did not return for follow-up, or had incomplete data were excluded from the analysis.

\section{RESULTS}

- Of the 233 patients identified, 17 were excluded.

- Median dose was $25 \mathrm{mg}$ daily.

- Mean follow-up duration was 19 weeks.

\begin{tabular}{|lc|}
\hline BASELINE CHARACTERISTICS & \\
\hline Variable & Mean (SD) or $\mathrm{n}(\%)$ \\
\hline Number of patients & 216 \\
\hline Female & $90(42 \%)$ \\
\hline Age (years) & $59(11.6)$ \\
\hline Weight $(\mathrm{kg})$ & $79.9(18.8)$ \\
\hline $\mathrm{HbA}_{1 \mathrm{c}}(\%)$ & $8.76(1.72)$ \\
\hline Systolic blood pressure $(\mathrm{mmHg})$ & $136(17)$ \\
\hline Diastolic blood pressure $(\mathrm{mmHg})$ & $76(11)$ \\
\hline LDL cholesterol (mmol/l) & $2.30(0.77)$ \\
\hline Estimated GFR (ml/min/1.73m²) & $80(14)$ \\
\hline Insulin therapy at baseline & $125(58 \%)$ \\
\hline CVD at baseline & $77(36 \%)$ \\
\hline
\end{tabular}

Figure 1: Mean treatment outcomes with empagliflozin
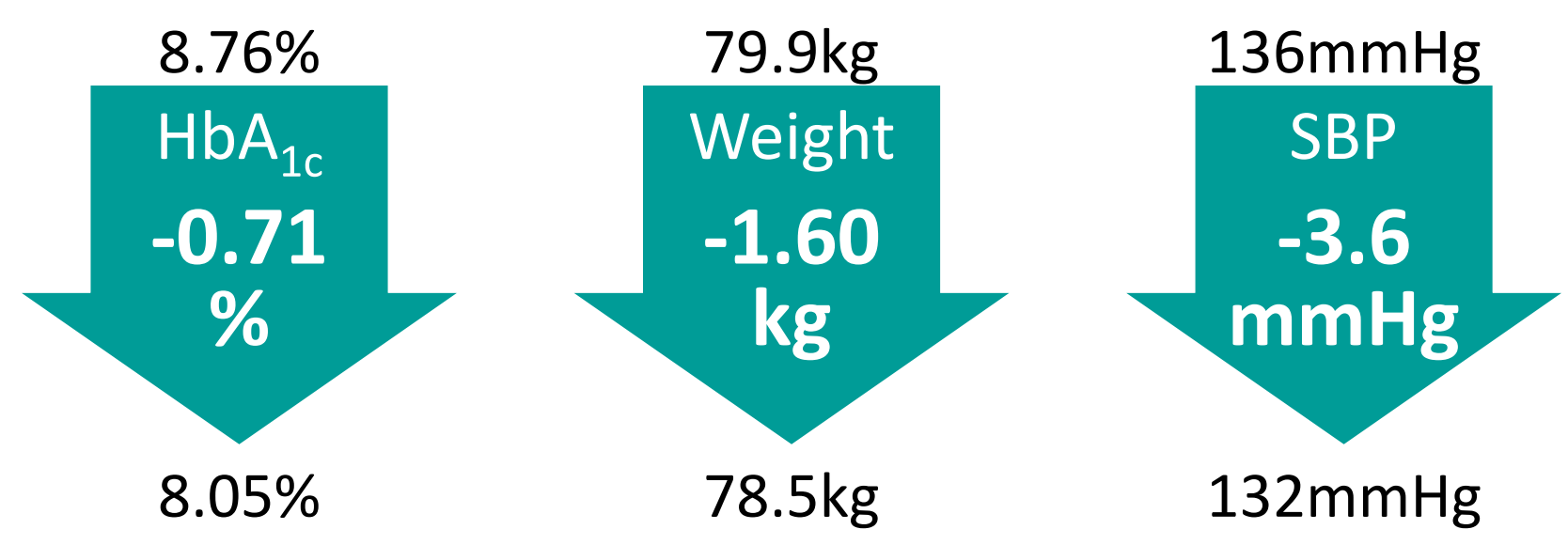

Figure 2: $\mathrm{HbA}_{1 \mathrm{c}}(\%)$ change by baseline $\mathrm{HbA}_{1 \mathrm{c}}$

Figure 3: Weight $(\mathrm{kg})$ change by baseline weight

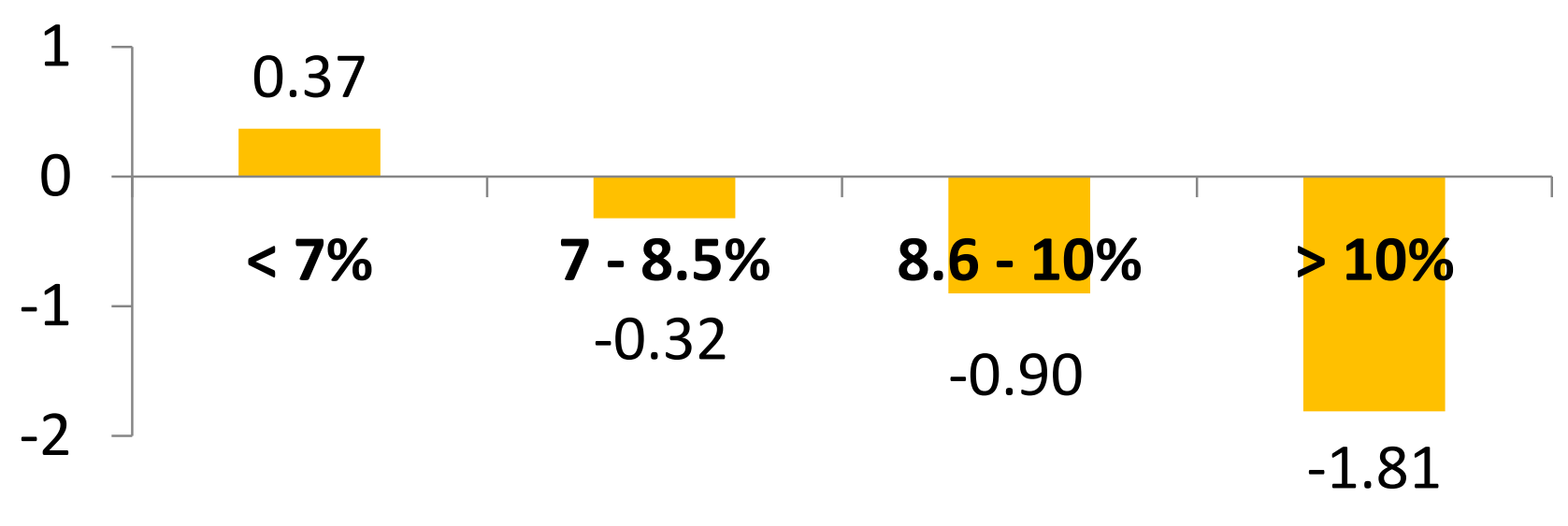

Figure 4: Systolic BP (SBP) (mmHg) change by baseline SBP$$
\begin{aligned}
& 0 \\
& -1 \\
& -2 \\
& -3
\end{aligned}
$$

$-1$

$-2$

$-3$

$-4$

\begin{tabular}{|c|c|c|}
\hline$<60 \mathrm{~kg}$ & $61-80 \mathrm{~kg}$ & $81-100 \mathrm{~kg}$ \\
\hline & -1.44 & -0.79 \\
\hline
\end{tabular}

$-3.97$

$\left.\begin{array}{r}15 \\ 5 \\ -5 \\ -15 \\ -15 \\ -25\end{array}\right] \quad \begin{aligned} & <120 \\ & \mathrm{mmHg}\end{aligned}$

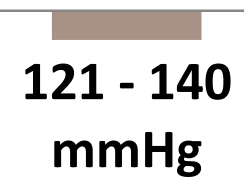

$-3.3$

$141-160$
$\mathrm{mmHg}$

$-8.10$

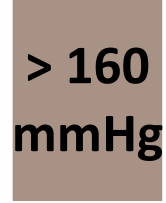

$-23.4$

- Patients who were on insulin at baseline $(n=125)$ with mean $\mathrm{HbA}_{1 \mathrm{c}}$ of $9.16 \%$ showed improvements $\left(\mathrm{HbA}_{1 \mathrm{c}}\right.$ : $-0.66 \%$; weight: $-1.05 \mathrm{~kg}$ ) on a stable insulin dose.

- GFR and LDL-C did not change significantly $\left(-2.33 \mathrm{ml} / \mathrm{min} / 1.73 \mathrm{~m}^{2}\right.$ and $0.01 \mathrm{mmol} / \mathrm{l}$ respectively).

- The most common adverse event was hypoglycaemia $(n=22)$, mostly in patients on concomitant sulphonylurea/insulin.

- Other adverse events were rare: polyuria $(n=3)$, dehydration $(n=2)$, postural hypotension $(n=2)$, urinary tract infection $(n=2)$, genital tract infection $(n=1)$ and diarrhoea $(n=1)$.

\section{CONCLUSION}

- The results of this real world study closely reflect those from the EMPA-REG trials.

- The majority of patients in this study had sub-optimally controlled diabetes and obesity with clinically significant $\mathrm{HbA}_{1 c}$, weight and BP reductions of similar magnitudes to those seen in the EMPA-REG trials ${ }^{1,2}$.

- The mean follow-up of 19 weeks in our study was comparable to that of the EMPA-REG MDI (empagliflozin plus multiple daily insulin)22.

- Empagliflozin was particularly effective for patients who were overweight or obese and had an insulin sparing effect.

- The drug was safe and well-tolerated. The most common adverse event was hypoglycaemia, mostly attributable to insulin, highlighting the need for insulin dose reduction on initiation of drug $^{2}$. 